\title{
O Brasil no mundo: conjecturas e cenários
}

\author{
SEBASTIÃO C. VELASCO E CRUZ e RICARDO SENNES
}

\begin{abstract}
A BERTO POR DOIs eventos dramáticos - a Guerra do Golfo e, logo a seguir, o colapso da União Soviética -, o debate sobre a natureza da ordem internacional pós-guerra fria ganhou novo impulso com o atentado do 11 de Setembro e as reações por ele desencadeadas. Seja qual for a caracterização do sistema internacional tida como a mais adequada, no centro da discussão estava, como continua a estar, o papel da superpotência. Vértice de um sistema unipolar? Elemento mais importante, mas com peso desigual nas diversas dimensões de poder envolvidas em um sistema sobremaneira complexo? Expressão proeminente de um ordenamento duradouro, ou traço característico de uma configuração marcadamente instável?
\end{abstract}

Não vamos entrar nesse debate. Em vez disso, adotando a postura prospectiva que informou todo o projeto "Brasil: O país no Futuro", procuraremos indicar algumas das linhas de força que deverão estabelecer o elo entre o sistema internacional presente e o que haverá no futuro, em um horizonte de vinte anos, seja qual for a feição que ele venha a apresentar.

A primeira delas diz respeito à trajetória dos Estados Unidos. A prudência aconselha projetar para o futuro previsível os valores relativos que asseguram hoje a proeminência indiscutível desse país no sistema internacional. Porém, a consideração mais detida de alguns aspectos abre espaço para interrogações.

O mais evidente deles tem a ver com a posição de sua economia. Apesar de seu tamanho e de seu dinamismo, a economia americana padece de problemas conhecidos que podem comprometê-la em médio ou longo prazos: o baixo nível de poupança, o grau muito elevado de endividamento (público e privado). Até o momento, o financiamento dos crescentes déficits, interno e externo, tem sido feito sem maior dificuldade, dada a disposição de investidores de todo o mundo de aplicarem seus ativos em títulos denominados em dólares. Mas o que ocorrerá se a confiança na solidez da economia americana e em sua capacidade de pagamento for, por algum motivo, abalada? Em que medida a consolidação do euro como moeda de reserva internacional tende a restringir os graus de liberdade da política econômica dos Estados Unidos? A hipótese de uma crise financeira grave nesse país pode ser descartada?

A superioridade militar dos Estados Unidos parece ser o elemento mais consistente de sua condição presente de superpotência singular. No entanto, aqui também é preciso cuidado para dimensionar corretamente os dados. A su- 
premacia americana nesse campo está assentada em seu poderio nuclear, em sua enorme dianteira no desenvolvimento e aplicação de armas de última geração, na capacidade única de projeção de poder em escala global, pela pujança de suas forças aérea e naval e pelo sistema de bases militares - mais de 720, espalhadas por todo o mundo. ${ }^{1}$ Nem por isso esse poder é ilimitado. No tocante ao armamento nuclear, cabe observar o descasamento entre o tamanho e o potencial destrutivo do arsenal americano e a sua utilidade. É a percepção dessa defasagem que inspirou a redefinição estratégica expressa na Nuclear Posture Review, de 8 de janeiro de 2002. Trata-se, para os planejadores americanos, de dar maior credibilidade à ameaça atômica por meio do desenvolvimento de artefatos de baixa potência, passíveis de serem empregados para a consecução de objetivos táticos. Seus defensores apresentam esse programa como indispensável para combater a proliferação das armas de destruição de massa; seus críticos denunciam o seu efeito dissolvente, afirmando que o referido programa atingiria de morte o regime de proliferação nuclear. Seja como for, por enquanto os planos não saíram do papel e há dúvidas de que possam vir a fazê-lo em curto prazo (cf. International Institute..., 2003-2004, p.20ss).

Com pleno domínio aéreo e marítimo, e com as armas eletronicamente guiadas de que dispõem, os Estados Unidos detêm os meios para vencer qualquer conflito convencional em que possam estar envolvidos. O problema é que o desafio militar que enfrentam é de outra natureza. Para fazer face à guerra assimétrica, é preciso ocupar o terreno e incorrer em um número de baixas que a sociedade americana tem muita dificuldade em aceitar.

O segundo vetor de mudanças que gostaríamos de destacar consiste no processo de construção da União Européia. O ceticismo quanto a esse projeto é grande em muitos setores, e as divisões que vieram à tona na crise diplomática do ano passado só as fizeram aumentar. Para muitos analistas, sua última ampliação torna a União Européia menos unida ainda, e mais impotente em face do Estado norte-americano. No entanto, olhado em perspectiva, de 1952 - quando foi criada a Comunidade do Carvão e do Aço - aos dias de hoje o acervo acumulado pela Europa é impressionante. O último elemento incorporado nele foi o projeto de Constituição, aprovado em junho de 2004 pelo Conselho Europeu, contra a expectativa dos incrédulos. A rejeição desse texto nos referendos francês e holandês criou grande comoção, mas não é certo que o significado do episódio tenha sido negativo para o processo geral de construção da Europa como comunidade política.

Na produção de uma identidade européia nítida, a implantação da Política Externa e de Segurança Comum é decisiva. Sabemos como é forte a resistência que ela desperta. E devemos acrescentar agora uma referência à dificuldade de integrar as perspectivas de países de tradições e vínculos externos tão distintos quanto a Inglaterra, a França e a Alemanha, de cuja confluência depende em grande medida o futuro daquele projeto. No entanto, alguns fatores militam a favor de sua materialização. Um deles é a integração já em estágio avançado da 
indústria bélica européia (cf. Guay \& Callum, 2002); o outro é a problemática de segurança, a qual para Europa - que tem uma população muçulmana de mais de trinta milhões de indivíduos e faz fronteira com muitas das regiões mais conturbadas do planeta - afigura-se em termos muito distintos do que para o aliado americano.

Desde seus primórdios, o processo europeu foi marcado pela tensão entre federalistas e confederalistas. Em cinqüenta anos ele recebeu muitos atestados de óbito, e sobreviveu a todos. Mais, ele avançou dialeticamente, entre momentos de letargia e saltos. Como se comportará nas próximas décadas?

A terceira força a considerar neste breve exame é a ascensão impressionante da China. Hoje ela já ocupa a segunda posição entre as maiores economias do mundo, com um produto interno bruto, pelo critério da paridade de poder de compra, de 6.435 trilhões de dólares, contra o PIB de 10.871 trilhões dos Estados Unidos (cf. World Bank, 2004). Se mantiver taxas de crescimento próximas das que vem acusando nos últimos vinte anos, a China terá se equiparada aos Estados Unidos nesse terreno no final do período que temos em vista. Mas é razoável esperar que as mantenha? Muitos analistas afirmam que não, e apontam uma série de distorções - situação pré-falimentar de milhares de empresas, fragilidade do sistema bancário, abarrotado de créditos irrecuperáveis - que a condenariam a se debater em grave crise financeira em prazo breve. Mesmo que tenham razão, como reagiria a China a uma crise dessa natureza? Com que prontidão conseguiria superá-la?

No plano geoestratégico também as questões se multiplicam. Há de saída o problema com Taiwan, que pode evoluir, em prazo relativamente curto, para uma crise de graves conseqüências envolvendo uma prova de força direta com os Estados Unidos. A China vem se preparando para essa eventualidade, e a comparação ingênua do orçamento militar dos dois países pouco nos diz sobre o seu grau de sucesso. Pelos dados oficiais, em 2002 a China teria gasto cerca de vinte bilhões de dólares em defesa, mas, segundo as estimativas do Ministério de Defesa dos Estados Unidos, os valores reais podem ter sido pelo menos três vezes maiores (cf. Department of Defense, 2003). Além dos problemas de imprecisão e baixa fidedignidade dos dados, a comparação é prejudicada ainda pelas distorções provocadas pela conversão ao dólar. Parte do gasto militar é realizada na aquisição de equipamentos ou em contratos de assistências, e está corretamente refletida quando expressa em moeda internacional. Mas o mesmo não vale para $o$ gasto correspondente à compra de material na própria China e ao dispêndio com soldos e salários (que respondem por fração importante do gasto total - $38 \%$ nos Estados Unidos, mais de 70\% na Europa): se o critério da paridade de poder de compra fosse utilizado na estimativa dessa parcela do gasto, o orçamento militar chinês se revelaria muito maior.

Taiwan não é a única área de atrito nas relações estratégicas entre a China e os Estados Unidos. O projeto de defesa antimíssil é encarado pela China como 
uma grande ameaça, que se torna maior ainda pela extensão deste ao Japão. Para fazer face a ela, a China conta, entre outras coisas, com sua capacidade de produção de mísseis balísticos intercontinentais em número tal que nenhum sistema de defesa poderia deter, e com o desenvolvimento de sistemas anti-satélites e outros dispositivos de uma futura "força de dissuasão exo-atmosférica", que incluiria lasers e mísseis capazes de destruir satélites, já em fase de pesquisa no presente (cf. Urayama, 2004). Para levar a efeito esse esforço de modernização e fortalecimento de seu aparato bélico, a China se vale fortemente da cooperação com a Rússia, e procura fazer avançar, nesse domínio também, a densa relação que mantém com a União Européia (cf. Ministry of Foreing Affairs..., 2003).

Para a China, as prioridades mais elevadas continuam sendo o desenvolvimento nacional, a manutenção das altas taxas de crescimento econômico e a promoção das condições internacionais mais propícias à consecução desses objetivos. Entre essas, incluem-se a paz e um ambiente seguro. Mas, como a segurança é um bem relativo, os esforços que a China faz para obtê-lo deixam em aberto várias interrogações sobre o futuro.

Se a intenção, neste artigo, fosse fazer um levantamento exaustivo, deveríamos acrescentar referências explícitas a vários outros temas. Como a recuperação econômica e os conflitos étnicos na Rússia; o desenrolar da crise no Oriente Médio - com ênfase na guerra suja no Iraque, na desestabilização de regimes tradicionais da região e na crise já avançada em torno do programa nuclear iraniano -, e a lenta, mas aparentemente segura, elevação da Índia à condição de grande potência, entre outros. Mas não é preciso. O que buscamos foi apontar apenas algumas das grandes forças que contribuirão certamente para moldar o sistema internacional nos próximos vinte anos. Qual tende a ser a sua configuração nesse horizonte de tempo? Manterá esse sistema a configuração unipolar que apresenta hoje, ou se deslocará em direção a uma estrutura multipolar, segundo a hipótese incorporada no planejamento estratégico de vários países, entre os quais a França e a China, e sustentada por alguns especialistas mais renomados da área? (cf. Waltz, 2002; Kupchan, 2002 e 2003; Todd, 2002).

Caso a primeira alternativa se revele verdadeira, qual tende a ser a natureza desse sistema unipolar: ele avançará no sentido de uma integração crescente, nos planos econômico, político, cultural e geoestratégico, do centro metropolitano os Estados Unidos e os países integrantes do bloco ocidental - atingindo essa um ponto tão elevado que não caberia mais falar de seus elementos constitutivos como estados distintos, mas como partes de um único sistema estatal, ${ }^{2}$ ou, pelo contrário, realizar-se-á pela acentuação das assimetrias no próprio centro do sistema, o que instituiria o Estado mais forte em sede de um império global? ${ }^{3}$

A reflexão sobre os delineamentos da nova ordem internacional em emergência no mundo do pós-guerra fria não é nova para a diplomacia brasileira, embora os acontecimentos desencadeados pelo 11 de Setembro tenham lhe conferido uma importância nova. Hoje, como na década passada, a percepção é clara 
de que o futuro é incerto. Para um país intermediário, afastado das áreas críticas de tensão internacional, como é o caso do Brasil, trata-se de definir uma estratégia de inserção internacional que leve em conta as três possibilidades antes mencionadas.

Elaborados com base nas respostas ao questionário relativo à dimensão global do Projeto "Brasil 3 Tempos", os cenários que apresentamos a seguir podem contribuir para essa tarefa. Dois deles - o "cenário mais provável" e o "cenário desejável" - sistematizam os resultados colhidos por meio daquele instrumento, ao observar o critério da média das probabilidade atribuídas pelos respondentes aos diferentes eventos sobre cuja ocorrência estavam sendo sondados. Os dois cenários contrastantes foram construídos a partir de procedimento que levou em conta o esquema de interconexões causais resultante da aplicação do modelo lógico de análise empregado pela equipe do IEA, bem como a literatura internacional relevante sobre o tema. Nesse sentido, mais do que criações pessoais dos autores do presente artigo, os cenários, em seu conjunto, representam o produto do esforço coletivo de todos os participantes da pesquisa.

\section{Cenário mais provável: Desconcentração conflituosa}

Nesse cenário, a primazia dos Estados Unidos na economia e na política mundiais se vê reduzida, pela ocorrência de um dos eventos a seguir, ou de sua ação conjugada: o aumento do poder econômico e militar da China, e a afirmação da identidade política da União Européia, por intermédio de uma Constituição própria e de uma Política Externa e de Segurança Comum (Pesce) efetiva, com capacidade independente de planejamento estratégico. Esse resultado é reforçado ainda por dois outros eventos: a ascensão da Índia e a integração da Rússia na União Européia.

A transição para um sistema dotado de vários pólos de poder é o elemento central nesse cenário. Mas o elemento que o distingue é a maneira como ela se processa. Nesse cenário, a desconcentração se opera de forma conflituosa, pela emergência de competidores com meios e disposição para contestar o papel de liderança da superpotência na condução dos assuntos internacionais.

Nesse contexto, manifestações recorrentes de discordância sobre questões relevantes aumentam as tensões entre os principais atores da política internacional, que se lançam em jogos de aliança envolvendo também as potências pequenas e médias.

Em várias partes do mundo, conflitos étnicos e religiosos geram situações críticas, mas as discrepâncias entre as grandes potências inibem as intervenções internacionais para saná-las. Embora as tensões no Oriente Médio continuem elevadas, os Estados Unidos reduzem sua presença militar na região, pela dificuldade de arcar com os custos econômicos e políticos nela implicados.

A persistência de fatores de crise nessa e em outras regiões do mundo cria condições favoráveis para organizações terroristas, que intensificam sua atividade. 
No plano das relações econômicas, as divergências entre os principais atores levam à multiplicação de acordos minilateralistas, em detrimento do sistema multilateral. Em todos os níveis, decresce a importância e a participação das ONG em organismos multilaterais, que passam a enfrentar sérias dificuldades.

Diante da emergência e a desconcentração dos pólos políticos e econômicos de relevância global, alteram-se as bases para a inserção internacional do Brasil.

Esse contexto favorece o aumento da importância do Brasil no cenário internacional como corolário de seu fortalecimento econômico e institucional, de sua presença regional consolidada. Porém, o enfraquecimento dos foros multilaterais como ONU e OMC e a forte divergência política entre as principais potências, velhas e novas, reduzem a importância desses foros como meio de ação internacional do país.

Avança de maneira constante a integração física da América do Sul, dada as necessidades geradas pelo aumento da integração econômica regional e a disposição estratégica do Brasil e dos países da região de criar uma identidade política sul-americana. O Brasil se consolida como liderança e coordenador estratégico desse processo combinado, com forte reflexo na sua presença política internacional. O baixo consenso internacional reduz a participação das organizações de fomento internacional (BID, Bird e outras agências) no apoio a esse projeto.

Desse processo de integração resulta maior estabilidade e ocupação econômica e social das zonas fronteiriças e do interior do continente, reduzindo a desigualdade econômica regional. Reduzem-se, assim, áreas de tensão social e política nas fronteiras entre os países.

Reduz-se também a presença militar nas fronteiras, as quais passam a ser controladas por autoridades civis. Os Estados Unidos não logram convencer os países da região a engajar suas forças armadas em programa conjunto e integrado focado nos problemas fronteiriços, como o combate ao crime organizado e ao narcotráfico. As fronteiras seguem vigiadas, quando necessário, pelas respectivas forças armadas.

As reservas indígenas se estabilizam sem novas pressões por ampliação ou pressão para o controle internacional da Amazônia.

No âmbito econômico multilateral, a redução da efetividade dos acordos comerciais diminui as garantias de acesso a mercado para os produtos agrícolas brasileiros. A abertura de novos mercados como China, Índia, Rússia, Oriente Médio compensa em parte a redução de acesso via OMC.

Aumenta, ainda que de forma lenta, a participação das fontes renováveis na matriz energética mundial, ao mesmo tempo que mudanças climáticas se acentuam pela falta de acordo multilateral sobre o tema.

Tal ambiente permite o aumento das exportações brasileiras e a redução da relação dívida externa/PIB, com boa repercussão para o desempenho econômico do país. Discordâncias entre as grandes potências nos foros econômicos multilaterais obstam a adoção generalizada de normas internacionais restritivas à implementação de políticas heterodoxas de fomento. 


\section{Cenário desejado: Multipolaridade benigna}

Nesse cenário, cria-se um maior equilíbrio de forças entre os Estados Unidos, a União Européia e a China, consolidando-se um mundo multipolar com fortalecimento das instituições regionais e multilaterais. Assiste-se, como no cenário da desconcentração conflituosa, à perda de poder relativo do Estado norte-americano, mas a passagem para a nova configuração do sistema internacional se dá, aqui, de forma organizada e sob liderança dos próprios Estados Unidos. Nesse ordenamento, a China emerge como grande potência econômica e política, e reforça as instituições internacionais vigentes. A União Européia implementa a sua Política Externa e de Segurança Comum e integra com sucesso a Rússia. A Índia avança em seu processo de consolidação como economia altamente dinâmica e contribui fortemente para a montagem de esquemas de cooperação entre países em desenvolvimento.

A distribuição menos concentrada do poder internacional contribui para a tolerância entre as culturas, o que reduz o número de crises que demandam intervenções internacionais.

No Oriente Médio, a solução negociada da questão palestina e a estabilização de regimes moderados diminuem as tensões políticas e livram a região da presença militar estrangeira.

A combinação de maior estabilidade política internacional e combate policial eficiente, com cooperação entre os organismos nacionais envolvidos, diminui significativamente a ameaça terrorista.

Nesse cenário, a geração de normas internacionais flexíveis estimula a adoção de políticas de desenvolvimento adequadas às circunstâncias e às necessidades dos países. As ONG participam ativamente das decisões em negócios internacionais, multiplicando-se os acordos no contexto de organizações multilaterais revigoradas.

Caracterizado por forte concerto entre pólos políticos e econômicos, velhos e novos, gera-se nesse cenário importante reforço das instituições internacionais e processos decisórios multilaterais, ampliando o espaço para a projeção política e econômica do Brasil. Tanto o histórico do Brasil ante essas instituições como sua consolidação como liderança sul-americana o credenciam para ocupar lugar de destaque nos principais foros internacionais.

O Brasil logra um crescimento econômico sustentável e equilibrado e, com base nisso, reforça suas estratégias regionais tornando-se o pólo articulador do processo de integração econômica e infra-estrutural da região (IRSA) com apoio das instituições multilaterais (BID, Bird, CAF e agências de desenvolvimento européias, japonesas etc.). Avança também o respaldo por todos os países da região à definição de metas comuns econômicas e sociais.

O aumento substancial da integração econômica e social da região sustenta-se com base na consolidação da integração física e na disposição estratégica de criar uma identidade política sul-americana. 
Desse processo de integração, resulta maior estabilidade na ocupação econômica e social das zonas fronteiriças e do interior do continente, reduzindo a desigualdade econômica regional. Reduzem-se assim significativamente áreas de tensão social e política nas fronteiras entre os países. Os Estados Unidos retiramse da função de polícia antidrogas da Colômbia e desmobiliza sua política de constituição de uma força comum regional de combate ao crime organizado e proteção militar das fronteiras.

Politicas adequadas ao controle de reservas indigenas e da Amazônia

$\mathrm{O}$ ambiente internacional estabilizado e o reforço das normas comerciais abrem espaço para forte expansão das exportações agrícolas do país. Reforça essa condição o avanço dos acordos e a tecnologia para uso de fontes renováveis de energia, em especial os energetic crops. A ratificação dos acordos climáticos previne mudanças nas condições de produção de alimentos.

O crescimento sustentável econômico e das exportações permite ao país reduzir de forma significativa seu endividamento externo e trazer a níveis aceitáveis sua vulnerabilidade internacional.

Normas internacionais flexíveis abrem espaço para a adoção de políticas de desenvolvimento adequadas às circunstâncias e às necessidades dos países, combinando compromissos de abertura comercial com garantias de maior equilíbrio nos ganhos econômicos derivados dela.

\section{Cenário contrastante 1: Unipolar consolidado}

Nesse cenário, os Estados Unidos implementam com êxito a estratégia de perpetuar a configuração unipolar do sistema internacional que emergiu com o colapso da União Soviética, apoiados no dinamismo de sua economia, no controle exercido sobre os circuitos financeiros internacionais e em seu formidável aparato bélico. Detentores de supremacia inconteste na política e na economia mundial, os Estados Unidos mantêm dentro de limites aceitáveis o poderio ascendente da China, mediante a preservação de presença militar decisiva na Ásia, do estímulo aos anseios de independência de Taiwan, do apoio conferido à Índia, e da atribuição de novo papel ao Japão no sistema de segurança regional. Da mesma forma, valendo-se das diferenças de interesses e pontos de vista entre os países europeus, os Estados Unidos bloqueiam o projeto de uma política externa e de segurança autônoma, mantendo a União Européia sob sua estrita dependência no plano geoestratégico. Com sua política de ampliação da Otan e de seu sistema de bases militares, os Estados Unidos elevam a sensação de insegurança na Federação Russa, que passa a defrontar-se com demandas separatistas intensas em várias regiões e tem dificuldades crescentes para manter a sua integridade.

Nesse contexto, multiplicam-se as intervenções internacionais em situações de crise geradas por conflitos étnicos e religiosos. No Oriente Médio, os Estados Unidos mantêm sua presença militar, com mobilização crescente de tropas estrangeiras sob o seu comando efetivo. 
Marcadamente unilateralista, a conduta internacional dos Estados Unidos é apoiada pela maioria dos governos, apesar da oposição que ela suscita em amplos setores da opinião pública. O poder incontrastável dos Estados Unidos, a universalidade de seus engajamentos e o caráter imperativo de sua política provocam resistências disseminadas, que se traduzem com freqüência em formas irregulares de ação militar e em atos terroristas.

No cenário unipolar consolidado, diminui a importância e a participação das ONG nos organismos multilaterais, que perdem influência na gestão dos assuntos internacionais. Nele, a potência hegemônica tende a valer-se de acordos bilaterais ou minilaterais para obter a adesão generalizada a normas internacionais que restringem severamente a capacidade dos países de implementar a seu critério políticas públicas.

Em decorrência de um ordenamento internacional fortemente hegemonizado pelos Estados Unidos, e sua projeção na região sul-americana, o Brasil mantém certa presença na América do Sul, mas não consolida sua condição de liderança regional. Tolhido na sua condição de pólo articulador regional, o Brasil investe pouco na integração infra-estrutural, concentrando suas apostas na ampliação de seus vínculos com as economias centrais.

Persistindo a baixa integração econômica e infra-estrutural da região, aprofunda-se a desigualdade econômica regional e a concentração do crescimento econômico em torno de algumas regiões metropolitanas. Proliferam assim áreas de tensão social e política no interior do continente, gerando pressões nas fronteiras entre os países.

Sob forte pressão dos Estados Unidos, vinga a proposta de utilização das forças armadas da região, sob a liderança das forças armadas norte-americanas, para lidar com os problemas fronteiriços, combater o crime organizado e o narcotráfico. Essas forças também seriam utilizadas em caso de instabilidade política nos países da região.

Com pouco espaço para a ampliação das ações políticas reivindicatórias, as reservas indígenas se estabilizam sem novas pressões por ampliação e diminui a pressão para o controle internacional da Amazônia.

Tal contexto impacta negativamente as tentativas do país de ampliar sua influência política no plano global, seja via presença nos foros multilaterais seja nas suas relações com outras regiões e países não dominantes.

As exportações brasileiras agropecuárias seguem se ampliando, em razão dos ganhos de produtividade e da redução gradual das barreiras comerciais nos mercados centrais. Contudo, o avanço lento da utilização de fontes alternativas de energia renovável faz que o Brasil se beneficie apenas marginalmente do mercado derivado dessas tecnologias (certificados de carbono, vendas de etanol) e de energetic crops (óleos vegetais etc.).

A ampliação apenas gradual das exportações do país mantém a dívida externa em dimensões exageradas perante o PIB, permanecendo forte a vulnerabilidade 
internacional do país e, em conseqüência, a situação econômica instável e o baixo crescimento. A ampliação dos acordos internacionais de corte liberal restringe a possibilidade de adoção de políticas econômicas heterodoxas e de fomento.

\section{Cenário contrastante 2: Ordem liberal cosmopolita}

Nesse cenário, a identidade de interesses e de valores básicos entre Europa, Japão e Estados Unidos cria condições para uma gestão compartilhada dos assuntos internacionais, que passa a se fazer cada vez mais por meio de entendimentos estabelecidos no interior de redes globais associando burocracias públicas e privadas, o que tende a privar as questões relativas à primazia de determinado Estado na política mundial de todo sentido. Nesse contexto, as divergências entre Europa e Estados Unidos no plano da segurança estão superadas, operando-se entre os parceiros uma divisão funcional de trabalho que preserva intacto o papel integrador da Otan. Plenamente ajustada aos parâmetros econômicos e políticos predominantes em escala global, a China mantém seu dinamismo e se consolida como um dos principais pólos de crescimento da economia mundial. A Rússia integra-se à União Européia, depois de implementar as reformas requeridas para sua inclusão. E a Índia, com uma economia muito mais aberta do que no presente, converte-se em país líder em segmentos de alta tecnologia.

O elevado nível de consenso entre os principais atores da cena internacional que caracteriza esse cenário facilita a montagem de operações de intervenção em casos de crise decorrentes de conflitos étnicos e religiosos, bem como em casos de crises políticas resultantes do estabelecimento de regimes que atentem contra os padrões ocidentais de legitimidade.

No Oriente Médio - e em outras regiões, sempre que necessária -, a presença militar estrangeira se fará sob a bandeira da ONU.

Nesse cenário, a ação conjunta da "comunidade internacional” e a adoção de políticas compensatórias em regiões críticas mantêm sob controle os níveis de tensão internacional e diminuem a ameaça do terrorismo.

$\mathrm{Na}$ esfera econômica, a geração de normas globais rigorosas sobre um conjunto crescente de temas reduz a margem de liberdade dos estados para a adoção de políticas domésticas e politiza as negociações internacionais. Em estreita associação com esse fenômeno, verifica-se um fortalecimento expressivo das ONG nos organismos multilaterais e na gestão das políticas públicas, com reconhecimento formal de seu papel no processo de tomada de decisões.

Nesse domínio, os interesses dos principais atores do sistema internacional podem diferir de maneira significativa, mas a convergência que existe entre eles no plano político e valorativo permite a busca de soluções negociadas, em fóruns multilaterais, para os problemas que dificultam o funcionamento dos diferentes regimes.

O ordenamento internacional hegemonizado por uma aliança atlântica liberal e cosmopolita abre espaço para o avanço gradual, mas consistente, da presença política e econômica do Brasil na região sul-americana. Tal condição favorece um maior concerto entre as nações do continente e maior estabilidade política. 
Consolidando-se como liderança regional, o Brasil passa a investir e coordenar um programa de integração da infra-estrutura regional (IRSA) com apoio das instituições multilaterais (BID, Bird, CAF e agências de desenvolvimento européias, japonesas etc.). Tal processo é mutuamente reforçado pelo aumento da integração econômica regional, comercial, financeira e produtiva.

Os países da região integram suas forças armadas em instituições de segurança coletiva, que se engajam em programa e ações voltadas a lidar com os problemas fronteiriços, com combate ao crime organizado e ao narcotráfico, passando a desenvolver ações de polícia.

Ganham força as demandas tanto por ampliação da demarcação dos territórios indígenas como por maior controle e monitoramento internacional da Amazônia.

Com base na sua forte presença regional, o Brasil logra ampliar presença e influência nos foros internacionais, consolidando-se como ator de relevo nas discussões e decisões globais. O Brasil amplia o poder de barganha com os países centrais.

$\mathrm{O}$ avanço das negociações multilaterais amplia o espaço para a efetivação da abertura do mercado agrícola mundial, com forte impacto nas exportações do país. Também o avanço na utilização das tecnologias e legislações favoráveis ao uso de energia renováveis gera impacto favorável para o setor dos energetic crops do Brasil.

O avanço rápido e sustentável das exportações agrícolas permite uma redução significativa da dívida externa do país e, portanto, reduz sua vulnerabilidade e os demais problemas derivados dela. Contudo, o avanço de acordos internacionais focado em livre-comércio restringe espaço para políticas de desenvolvimento e fomento.

\section{Indicações sobre o Brasil no futuro}

Nosso argumento está centrado na idéia de que o cenário internacional futuro será definido pela resultante da interação de três pólos políticos, econômicos e militares: os Estados Unidos, a Europa e a China. A própria dinâmica interna desses pólos irá definir suas capacidades de atuar de forma mais ou menos efetiva na arena internacional. Algumas combinações possíveis dessa integração foram apresentadas na forma de cenários com o intuito de balizar a reflexão sobre possibilidades e limites para a atuação internacional do Brasil.

Ou seja, diferentemente dos exercícios sobre a inserção internacional do Brasil calcada em sua própria identidade, vocação, interesses e valores, este texto apresenta espaços, ameaças e restrições para a projeção internacional do país tomando por base o jogo geopolítico e geoeconômico mundial.

Interessa salientar a partir deste trabalho alguns traços do que poderá vir a ser a inserção internacional do Brasil diante de cada um dos cenários indicados antes. Diferentes conformações da ordem internacional certamente impactarão o Brasil e seu entorno, mas não necessariamente implicarão mudanças radicais nas possibilidades de projeção do país no exterior. 
De modo geral, a projeção é que o Brasil seguirá avançando rumo a uma maior presença e participação política e econômica mundial, de alguma forma reduzindo o gap entre a proporção dos seus atributos territoriais, econômicos, populacionais e políticos e sua pequena influência política e econômica internacional.

Também predomina a percepção de que a projeção internacional do Brasil tem na região sul-americana sua base principal. Projeta-se que o Brasil provavelmente seguirá ampliando sua presença na região sul-americana para além de suas já tradicionais exportações de produtos industriais. Deverá diversificar sua presença econômica na região seja em projetos de infra-estrutura seja por meio de maior integração logística e de comunicação, seja no que tange à maior nível de integração produtiva, investimentos externos regionais e convergência regulatória.

Também no campo político e de segurança, o Brasil tende a ampliar sua participação na vida da região, em particular no que tange às crises políticas e institucionais, assim como a ampliar os fóruns de consulta e negociações com recortes específicos. Essas tendências, contudo, seriam mais ou menos acentuadas conforme os impulsos do ordenamento internacional, embora não de forma radical.

Por exemplo, projeta-se que a presença do país ganhará diferentes roupagens, dependendo do papel das instituições internacionais. Tanto no cenário hipotético de Desconcentração conflituosa como do Unipolar consolidado, reduz-se drasticamente a capacidade de essas instituições prevalecerem sobre as políticas e interesses das potências dominantes. Em decorrência, o espaço internacional do Brasil estará mais associado à participação em fóruns e associações bilaterais e minilaterais do que multilaterais, e bastante menos calcada em regras e arbitragens. Já nos dois outros cenários, a projeção internacional do país passaria a se beneficiar de sua já razoável presença em fóruns como a OMC e a ONU.

No campo regional, a capacidade de o Brasil se consolidar como liderança regional está condicionada à maior ou menor predominância política global dos Estados Unidos. Nesse caso, apenas no cenário da Unipolaridade consolidada é que a agenda de segurança dos Estados Unidos na região se sobreporá às vertentes integracionistas do Brasil, tanto infra-estruturais como políticas e econômicas. Os demais cenários indicam que o Brasil deverá avançar na implementação de uma agenda regional combinando certa liderança com integração e cooperação.

Outra variável-chave para avaliar as diferentes possibilidades de o país se projetar no jogo internacional é a maior ou menor vulnerabilidade financeira do país. As variáveis-chave aqui são: a maior ou menor abertura do comércio agrícola mundial, a maior ou menor demanda internacional por energetic crops, maior ou menor estabilidade das regras econômicas, assim como o maior ou menor espaço para a prática de políticas ativas pró-desenvolvimento. Talvez aqui repouse o aspecto mais sensível sobre o futuro da inserção internacional do país. Cenários fortemente desfavoráveis nessa dimensão (por exemplo, forte restrições ou instabilidade das regras nas exportações agrícolas, somadas com baixa demanda por energia renovável e pouco espaço para aplicação de políticas ativas nas áreas industriais, 
tecnológicas e financeiras) são vistos como fortemente impactantes sobre a capacidade do país em sustentar seus projetos políticos e econômicos internacionais.

Dessa forma, o país segue com razoável potencial para ampliar o grau de influência política internacional, em particular na região sul-americana, e será capaz de sustentar minimamente essas pretensões em vários cenários geopolíticos. Contudo, o calcanhar-de-aquiles desse processo segue sendo a enorme vulnerabilidade econômica e financeira do país que, nos cenários mais negativos, pode comprometer de forma sensível a sua capacidade de ação.

Notas

I Sem falar das bases que os Estados Unidos mantêm disfarçadamente, sob a bandeira de outros países. Sobre o tema, ver Johnsonm (2004).

2 Essa hipótese, que já se insinua em trabalhos de autores prestigiados, como Robert Jervis e John Ikenberry, e que foi desenvolvida sistematicamente em obra importante de Martin Shaw, tem afinidades claras com o discurso dos governos de Clinton e de Tony Blair (cf. Ikenberry, 2001; Jervis, 2000; Shaw, 2000).

3 Essa hipótese, que não é nova, vem ganhando respeitabilidade acadêmica crescente nos últimos anos. Para apresentações elaboradas desse ponto de vista, ver Gowan (2004), Bacevitch (2002) e Fergunson (2004).

Referências bibliográficas

BACEVITCH, D. J. American Empire. The Realities and Consequences of U. S. Diplomacy. Cambridge, Ms.: Harvard University Press, 2002.

DEPARTMENT of Defense. Report to Congress. Annual Report on The Military Power of the People's Republic of China. Washington, D.C.: Department of Defense, 2003.

FERGUnSON, N. Colossus. The Price of America's Empire. New York: The Penguin Press, 2004.

GOWAN, P. Contemporary intra-core relations and world systems theory. Journal of World-Systems Research, v.10, n.2, p. 471-500, Summer 2004.

GUAY, T.; CALLUM, R. The transformation and future prospects of Europe's defense industry. International Affairs, v.78, n.4, p.757-76, 2002.

IKENBERRY, G. J. American power and the empire of capitalist democracy. In: COX, M.; DUNNE, T.; BOOTH, K. (Ed.) Empires, Systems and States. Cambridge: Cambridge University Press, 2001. p.191-212.

INTERNATIONAL Institute for Strategic Studies. Strategic Survey, 2003-2004.

JERVIS, R. Theories of War in an Era of Leading-Power Peace: Presidential Addres, American Political Science Association, 2001. American Political Science Review, v.96, n.1, p.1-14, 2000.

JOHNSONM, C. The Sorrows of Empire. Militarism, Secrecy, and the End of the Republic. New York: Metropolitan Books, 2004.

KUPCHAN, C. A. Hollow Hegemony or Stable Multipolarity? In: IKENBERRY, G. J. (Ed.) American Unrivaled. The future of the balance of power. Ithaca, London: Cornell University Press, 2002. p.68-97. 
KUPCHAN, C. A. The End of the American Era. U.S. foreign Policy and the geopolitics of the Twenty-First Century. New York: Alfred A. Knopf, 2003.

MINISTRY of Foreign Affairs of the People's Republic of China. China's EU Policy Paper, 13.10.2003.

SHAW, M. Theory of the Global State. London: Cambridge University Press, 2000.

TODD, E. Après L’Empire. Essai sur la décomposition du système américain. Paris: Gallimard, 2002.

URAYAMA, K. China Debates Missile Defense. Survival, v.46, n.2, p.123-42, 2004.

WALTZ, K. N. Structural Realism after the Cold War. In: IKENBERRY, G. J. (Ed.) American Unrivaled. The future of the balance of power. Ithaca, London: Cornell University Press, 2002.

WORLD BANK. World Development Indicators Database. s. 1.: World Bank, Sept. 2004.

RESUMO - O PRESENTE artigo resume parte dos resultados de um amplo projeto sobre o Brasil ante cenários internacionais possíveis. Adotando a postura prospectiva que informou todo esse projeto, o artigo indica algumas das linhas de força que deverão estabelecer o elo entre o sistema internacional presente e o que haverá no futuro, em um horizonte de vinte anos, destacando entre outros o papel dos EUA, da Europa e da China nesse processo. Quatro cenários são utilizados como base para a análise do caso brasileiro: Desconcentração conflituosa, Multipolaridade benigna, Unipolar consolidado e Ordem liberal cosmopolita. Considera-se aqui o Brasil como um país intermediário, afastado das áreas críticas de tensão internacional, e que, portanto, dispõe de certa margem de manobra e razoável condição para definir suas estratégias internacionais.

PALAVRAS-CHAVE: Relações internacionais, Cenários, Unipolaridade, Multipolaridade, Brasil, Geopolítica, Ordem internacional, Política externa.

ABSTRACT - THIS article presents part of the results of a broad research about Brazil and international scenarios. Assuming the same prospective view of the research project, this article indicates a few current driving forces that will contribute to define international order in the future, in a 20 years perspective. The roles of the USA, Europe and China are highlighted in this analysis. Four scenarios are used as parameters for the analysis of the Brazilian case: conflictive deconcentration, benign multipolarity; consolidated unipolarity and cosmopolitan liberal order. We consider Brazil as an Intermediate State out of the critical areas of international conflict. We also consider that Brazil has certain margin for maneuver and reasonable amount of capacity to define its international strategies.

KErWORDs: International relations, Scenarios, Unipolarity, Multipolarity, Brazil, Geopolitic, International Order, Foreign Policy.

Sebastião C. Velasco e Cruzé professor do Instituto de Filosofia e Ciências Humanas da Unicamp e pesquisador do Centro de Estudos de Cultura Contemporânea (Cedec). Foi o coordenador da dimensão internacional do Projeto "Brasil 3 Tempos", do Instituto de Estudos Avançados da USP. @ - svelasco@globo.com

Ricardo Sennes é sócio-diretor da Prospectiva Consultoria Brasileira de Assuntos Internacionais. Foi o vice-coordenador da Dimensão internacional do Projeto "Brasil 3 Tempos”, do Instituto de Estudos Avançados da USP. @ - rsennes@uol.com.br

Recebido em 15.10.2005 e aceito em 10.11.2005. 